\title{
RACIONALIDAD CONSTITUCIONAL Y GARANTÍAS DEL PROCESO
}

\author{
SERGIOCHIARLONI ${ }^{(* *)}$
}

\begin{abstract}
Resumen
La racionalidad constitucional impone que las garantías procesales tengan en consideración de forma equilibrada los intereses de ambas partes que se ven contrapuestas en una controversia. El concepto de racionalidad es analizado por el autor como un valor que va más allá del ámbito del derecho, es decir como un elemento constitutivo del homo sapiens; motivo por el que entre constitucionalistas y filósofos del derecho se difunde la convicción de que el principio de racionalidad práctica ha asumido el rango de valor constitucional gracias a la constitucionalización de los derechos humanos. Todo ello es explicado en la prospectiva del proceso civil, donde el constituyente ha instituido la garantía del recurso con el objetivo de garantizar la igualdad en el tratamiento para las partes procesales.
\end{abstract}

Palabras clave: Racionalidad, constitución, proceso civil, garantías procesales, recursos.

\begin{abstract}
The Constitutional rationaliyt dictates that procedural safeguards will be balanced in order to consider the interests of both parts that in this case are opposed in a controversy. The concept of rationality is analized by the author as a value that goes beyond othe scope of the legal right., it means like a constitutive element of the Homo sapiens that is

(*) Este ensayo reproduce, con sucesivas aclaraciones y la añadidura de notas, una lección magistral realizada en el 2011 en la facultad de derecho de la universidad Sor Úrsula Benincasa de Nápoles destinado a los Estudios en homenaje a Diego Corapi.

Título original en italiano: Ragionevolezza costituzionale e garanzie del processo. Traducido al español por Yuri Tornero Cruzatt. Yuri Tornero es traductor del Centro de Estudios sobre América Latina de la Universidad de Bolonia. Miembro desde el 2013 de la "Associazione Italiana di Diritto Comparato". Cursa estudios de doctorado en Comparación Jurídica e Histórico Jurídica por la Università di Ferrara (Italia). Titulado de abogado en la Universidad Nacional Mayor de San Marcos. Ha realizado una estadía en el Max Planck Institute for European Legal History (MPIeR) Alemania.

(*m) Sergio Chiarloni. Profesor ordinario de Derecho Procesal Civil de la Universidad de Turín, además de profesor de Derecho Italiano en la Facultad de Derecho Jean Moulin, de la Université de Lyon 3 (Francia). Pertenece a la National Bar Association desde 1964. Es coeditor de diversas revistas: la "Nuova Giurisprudenza civile commentata", "Giurisprudenza italiana", "Rivista trimestrale di diritto e procedura civile", 1995 -present- Coeditor of the "Questione giustizia", Coeditor of the "Biblioteca di Diritto Processuale Civile".
\end{abstract}


the reason why between constitutionalists and philosophers of the law spead the conviction that the principle of practical rationality assumes the rank of constitutional value because of the Constitutionalization.

Keywords: Rationality, constitution, civil process, procesal guarantees, resources.

\section{Sumario}

1.- Introducción. 2.- Equilibrio como adecuación del instrumento respecto a su objetivo. La garantía constitucional del recurso en casación que se ha vuelto irrazonable por la variedad de los fines perseguidos. 3.- El principio de "justo proceso regulado por la ley": una cláusula general que resume las garantías formales previstas en el art. 111 del nuevo texto constitucional y al mismo tiempo "racionalmente" orientada a la justicia de la decisión. 4.- El irrazonable ejercicio de "justo proceso" y la inexistencia de un deber de verdad de las partes, como también de una eficaz sanción por negación de obedecer a la orden de exhibición. 5.- Equilibrio entre el derecho de acción y derecho de defensa en la disciplina de las notificaciones. 6.- El formalismo de las garantías. 7.- Una reconstrucción irrazonablemente desequilibrada en las relaciones entre principio de razonabilidad duradera del proceso y derecho de acción. 8.- La sanción de nulidad irrazonablemente aplicada a las sentencias de la tercera vía a causa de una errónea aplicación del principio del contradictorio.

\section{Introducción.}

Si pensamos en el uso del término racionalidad en el lenguaje común, definida como "la cualidad del actuar con equilibrio" vemos enseguida que la cantidad de especificaciones en el lenguaje técnico mantienen intacta la idea de base en los distintos ámbitos en la cual se aplica: Tanto en las respectivas particularidades como en el contexto de grandes dificultades reconstructivas debidas al hecho de que estamos ante la presencia de una técnica argumentativa basada en un concepto furtivo, ambiguo, polisémico ${ }^{1}$ cuando se trata de buscar en él un encuadramiento sistemático en un determinado sector.

Por lo tanto, para la filosofía política, la racionalidad está orientada en hacer coexistir la igualdad con la equidad en los sistemas democráticos pluralistas²; para la jurisprudencia Constitucional está destinada a delimitar los roles desempeñados entre un legislador elegido democráticamente y el garante de la Constitución, que es un órgano ajeno al circuito democrático ${ }^{3}$, para el derecho

Así, SPADARO, Conclusioni, en La Ragionevolezza nel Diritto, Turín 2002, 415.

Cfr. VIOLA, La ragionevolezza política secondo Rawls, en Vigna, Etiche e politiche della posmodernità, Milán 2003, 163 sgtes.

3 Sobre la racionalidad como técnica argumentativa reenvío al Archivio e Storia costituzionali, a cargo de M. Dogliani y M.G Losano, de donde bien emergen complejidades y complicaciones 
(www.dircost.unico.it/SentNet1.01/def/sn_descrizione_argomenti.shtml), del cual he extraído el siguiente esquema:

A. Técnicas utilizadas para producir la norma parámetro a través de la atribución - mediante ponderación/concretización - de significados específicos a enunciados constitucionales contenientes de principios

Ponderación como individualización del contenido mínimo esencial - (B1). Ponderación como individualización de la óptima proporción - (B2).

El procedimiento hermenéutico en el que consiste la ponderación entre principios constitucionales puede ser resumido en el siguiente modo:

a) Existe un conflicto entre el principio - entendido en forma genérica - en el cual puede ser reconducida la disposición $\mathrm{X}$ (es decir, la combinación entre las disposiciones A, B y C) y el principio - generalmente entendido - en el que puede ser reconducida la disposición Y (o bien, la combinación de las disposiciones $\mathrm{E}, \mathrm{F}$ y G);

b) Tal conflicto puede ser resuelto de dos formas: 1) individualizando la mejor proporción posible entre los dos principios; o bien 2) individualizando los límites desde los cuáles la comprensión de uno de los dos principios no puede ir;

c) En el primer caso la Corte definirá el punto de óptimo equilibrio, en el segundo caso definirá el contenido mínimo esencial de los principios en conflicto (o de aquel "agredido");

d) Pero la individualización de estos puntos (de equilibrio) o de estas líneas (delimitantes) deriva en la aceptación de la Corte:

De uno entre los tantos posibles criterios de justicia, los cuales, como Kelsen ha demostrado, encauzan todos - a excepción de la caridad - a ordenamientos de valores y de preferencias cuya existencia está presupuesta y aceptada por aquel que utiliza el criterio;

De un significado específico atribuido, frente al caso concreto, hacia aquel principio; $y$

e) Sobre la base de este específico significado atribuido a un particular principio de justicia - es decir, sobre la base de una "doble lectura" que individua el criterio de justicia idóneo para resolver el conflicto - el tribunal atribuye a las disposiciones constitucionales que constituyen los polos del conflicto en cuestión, los significados idóneos para resolverlo. En caso hubiera una óptima proporción se declararían inconstitucionales todos los significados de las disposiciones que no coincidan con aquello que exprime tal puntual equilibrio. En el caso de un significado mínimo esencial se declararán inconstitucionales solo los significados que se encuentren más allá del "confín".

En la hipótesis formulada precedentemente la Corte a través de la interpretación de las disposiciones en conflicto individua una norma parámetro (que define o el óptimo equilibrio o bien el confín inabarcable). Se podría pensar - en contrariedad con lo dicho en esta reconstrucción - la ponderación no derive de la aplicación de una norma, sino más bien que sea una técnica aplicativa que resuelva un dilema que no puede ser resuelto a través de una ulterior actividad interpretativa de las disposiciones en conflicto. Entonces, es necesario constatar que la Corte, cuando recurre a la técnica de la ponderación, opera la ponderación en sí, como si consistiera en la aplicación de una norma parámetro individuada a través de la interpretación de las disposiciones en conflicto.

Otros reconstruyen el procedimiento hermenéutico comúnmente definido de la ponderación entre principios constitucionales en términos diversos.

Considerando la ponderación no como un modo para aplicar los principios, sino más bien como un modo de elegir el principio aplicable en caso de conflicto, la ponderación misma es considerada actividad precedente a la aplicación (de uno u otro principio) y por tanto, cosa distinta a dicho principio. La aplicación del principio identificado consiste, desde esta óptica, en la "concretización" de dicho principio, es decir en la individualización de una regla hasta aquel 
administrativo está destinada a integrar el interés público con el interés de los privados involucrados en la actividad de la administración pública; para el

momento inexpresa - de configuración cerrada, indefectible, no genérica - que consienta la subsunción en otros casos imposible, dada la naturaleza genérica del principio.

Esta última reconstrucción no produce resultados tan distantes de aquella anteriormente descrita si se considera que la regla no expresada, que resulta de la concretización del principio, desarrolla la misma función respecto de aquellos que han sido definidos como el punto de óptimo equilibrio y el contenido mínimo esencial de los principios en conflicto.

B. Técnicas utilizadas para producir la norma parámetro a través de juicios de racionalidad que no sirven después para seleccionar posibles significados de enunciados constitucionales.

Justicia como conveniencia: Racionalidad instrumental (juicio de racionalidad formulada en términos de idoneidad, eficacia, proporcionalidad)-(G1)

Justicia como conveniencia: Racionalidad intersubjetiva (juicio de racionalidad que se puede formular en términos de igualdad) - (G2)

Justicia como conveniencia: Aplicaciones residuales del principio de racionalidad - (G3)

Existen frecuentes hipótesis en el parámetro de la Corte para decidir la inconstitucionalidad de una norma ordinaria, no consiste en un significado atribuido a una disposición constitucional: casos en los que el vínculo entre el parámetro del juicio y el enunciado del texto de la Constitución está interrumpido.

La utilización de tal tipo de parámetro puede darse:

a) Cuando una norma resulta ser contradictoria en relación al fin que el legislador, implícita o explícitamente, declara querer perseguir (incoherencia teleológica);

b) Cuando una norma resulta íntimamente contradictoria (incoherencia interna) o irreducible al sistema legislativo en el que debería inserirse, siendo por tanto irremediablemente no armonizable respecto de este (incoherencia sistémica); $y$

c) Cuando -más allá del campo de aplicación del principio de igualdad, es decir, allí donde la discrecionalidad legislativa no está vinculada por normas constitucionales- una relación jurídica aparece disciplinado en modo de poder sacrificar irracionalmente los intereses de una de las partes.

Este elenco no es y no puede ser taxativo porque la Corte hace valer, donde lo considere, criterios de racionalidad que considera presupuestos de la Constitución en su conjunto, pero que no pueden ser derivados por alguna disposición específica.

En todos estos casos la Corte aplica - más allá del modo con el que esgrime sus argumentacionesel criterio de la justicia como conveniencia, como adecuación de la norma al caso concreto. Utiliza como parámetro la norma justa que debería ser pero que no es: Aquella norma que el sentimiento de justicia del intérprete, de frente al caso concreto, percibe como ausente. Se trata de parámetros, por definición, ajenos a los enunciados del derecho escrito.

En las hipótesis consideradas lo que cuenta no es, en sí, el recurso a una regla de justicia, sino el hecho que tal regla no venga utilizada para seleccionar uno de los significados posibles de un enunciado. Si así fuere se trataría de un simple uso del criterio equitativo, criterio de contenido. Indefinible, pero que, utilizado para atribuir a un enunciado uno de sus significados posibles y para argumentar la preferencia por estos, realiza un rol idéntico al de los otros argumentos hermenéuticos. Aquello que diferencia las hipótesis examinadas ahora del uso del criterio equitativo estriba en que aquí el principio de justicia opera no como una regla sobre la interpretación del derecho, sino como una regla sobre su producción. 
derecho privado está orientada a integrar la autonomía negocial con la buena $\mathrm{fe}^{4}$.

Entonces, debido a que por convicción metodológica desde hace largo tiempo soy hostil al conceptualismo dogmático, y estoy convencido que cualquier lenguaje especializado no tiene sentido si no es traducible (sea bien a través de los largos y complicados pasajes) en los términos del lenguaje común, trataré de racionalidad y de las garantías procesales bajo la orientación de aquel "actuar con equilibrio" que he encontrado en la definición de un vocabulario.

Naturalmente, me doy cuenta de partir, incluso yo, con el nada ligero peso de un concepto vago y mal definido. Pero asimismo, estoy convencido que aquí la intuición juega un papel fundamental para poner en marcha el entendimiento, diciéndonos algo de gran valor: que la racionalidad es un valor que va más allá del ámbito del derecho: es un elemento constitutivo del homo sapiens, que lo contrapone al Hubris irracional del homo demens en una contraposición infinita de resultado incierto. Creo que a causa de este sobreentendido motivo que entre constitucionalistas y filósofos del derecho se difunde la convicción que el principio de racionalidad práctica ha asumido el rango de valor constitucional $^{5}$, gracias a la constitucionalización de los derechos humanos ${ }^{6}$.

Sin embargo, no nos debe asustar: asimismo en las ciencias de la naturaleza conceptos vagos y mal definidos $-\mathrm{y}$ a veces con un fuerte sentido metafórico (debido esto último a la transferencia de una rama científica a otra)- han constituido pilares fundamentales para la construcción (o la descripción) de teorías importantes. Algunas veces gracias a una fertilización cruzada ${ }^{7}$.

2. Equilibrio como adecuación del instrumento respecto a su objetivo. La garantía constitucional del recurso en casación que se ha vuelto irrazonable por la variedad de los fines perseguidos.

Creo poder decir que un instrumento está en equilibrio con las finalidades para las cuales ha sido pensado si es adecuado para conseguirlas. Ahora, hay garantías procesales previstas en la Constitución que no son valores en sí mismos en virtud a los principios, pero poseen mencionada característica

4 Cfr. ZORZETTO, Ragionevolezza, política del diritto e semiótica giuridica. Considerazioni in margine al libro Ragionevolezza e autonomia negoziale, in Diritto e questioni pubbliche 2010, 602 sgtes.

5 Cfr. RUGGERI, Ragionevolezza e valori, attraverso il prisma della giustizia costituzionale, in Diritto e società 2000, 567 sgtes.

6 VIOLA, Ragonevolezza, cooperazione e regola d'ora, en Ars interpretandi 2002, 110.

7 Basta pensar el "software" en la neurobiología o la "memoria" en la informática. 
instrumental y deben por tanto ser valoradas como razonables si son capaces de alcanzar los resultados para la cual han sido instituidas.

Esta característica va atribuida a la garantía del recurso de casación por violación de la ley en contra de todas las sentencias, prevista del artículo 111 de la Constitución italiana. Un órgano único y centralizado de suprema justicia tiene como función principal asegurar la uniforme interpretación de la ley como dice el artículo 65 del ordenamiento judiciario del 1942, respecto a las divergencias que se verifican frecuentemente en los "jueces de mérito" 8 . En la prospectiva del proceso civil, el constituyente ha instituido la garantía del recurso para los sujetos implicados en una controversia con el objetivo de garantizar la igualdad en el tratamiento, que de no ser asegurada conllevaría a la degradación del principio fundamental enunciado en el artículo 3.1 de la Constitución italiana.

Si bien la protección constitucional del recurso de casación ha fracasado en la obtención de la igualdad a través de la uniformidad de la jurisprudencia. Es la falta de filtros a los recursos, como sí está previsto en otros ordenamientos jurídicos, no solo en los del common law, aquello que ha hecho que los productos jurisprudenciales del Tribunal Supremo sean similares a los de un supermercado 9 , donde la parte que sucumbe encuentra frecuentemente, junto a aquellos contrarios, incluso precedentes favorables que pueden inducirla a probar suerte. Nos encontramos aquí frente a uno de los casos más eminentes y heterogéneos de los fines que persigue una norma procesal ${ }^{10}$. En particular,

8 El término original es "giudice di merito": aquellos jueces que conocen tanto los hechos como el derecho, estos pueden ser de primer grado como de segundo grado. En cambio a los jueces de la casación que solo conocen la correcta aplicación de la norma, a estos últimos se les denomina "giudice di legitimitá". (N. del T.)

9 La eficaz comparación es de Taruffo, Il vertice ambiguo, Boloña 1991, 103.

10 Puede ser interesante recordar que la heterogénesis de los fines ha asumido importancia en la jurisprudencia de la Corte, pero con resultados muy diversos: entendida como mutación sustitución en el tiempo de la ratio legis en relación a la originaria que no es compatible. Ha consentido rechazar cuestiones de inconstitucionalidad, gracias a una interpretación de adecuación basada en las nuevas finalidades de la norma, que consiente superar el análisis de racionabilidad. Cfr. Morrone, Corte costituzionale e principio generale di ragionevolezza, en La ragionevolezza nella ricerca scientifica eil suo ruolo specifico nel sapere giuridico, cuaderno monográfico 2007 de Nova juris interpretatio in odierna gentium communione, 239 ss., donde se recuerda la sentencia de la Corte Constitucional número 5/62, que declara la ilegitimidad de la prohibición de la venta y almacenamiento del conocido arroz integral, establecido en la posguerra en función a las exigencias generales de la alimentación nacional, a raíz de la violación del principio de reserva de ley en materia de libertad de empresa. Esta decisión es muy importante y de gran relevancia porque por vez primera se toma en consideración el problema de la heterogénesis de los fines en sede constitucional. La Corte Constitucional, efectivamente, reconoce al legislador la posibilidad 
la garantía del recurso contra todas las sentencias ha determinado la imposibilidad para la Corte de Casación asegurar la uniforme interpretación y aplicación de la ley. La razón es simple y puede estar contenida en un dicho popular: "tot capita to sententiae"11. Desde hace muchos años se da un aumento progresivo y numeroso de recursos, redoblados incluso en relación a los años cincuenta del siglo pasado, tanto así numerosos y en progresiva vía de aumento son los jueces llamados a decidirlos.

La consecuencia es evidente ante los ojos de todos. Añadiendo el desorden jurisprudencial al desorden que caracteriza la actividad de los parlamentos modernos, nuestra Corte Suprema presenta un panorama de pronunciamientos contrastantes entre "sección" y "sección", entre "Sezione semplice" y "sezione Unite" y a menudo, incluso al interior de la sezione, compresas las mismas "sezione Unite", sobre el hilo de ámbitos de (casi) contemporaneidad, que nada tienen que ver con las exigencias de una maduración consciente y de una evolución natural de la jurisprudencia, incluso porque se trata de contrastes relacionados con la interpretación y la aplicación de normas nada recientes. Bastará recordar el conjunto de contrastes realizados en artículos y así como en grandes volúmenes por un gran estudioso ${ }^{12}$. En relación al procesal civil existen casos recientes de contrastes en materia de admisibilidad del "recurso incidental condicionado" y de "cláusula abusiva" que regula la competencia territorial en los contratos del consumidor ${ }^{13}$.

de valorar (siempre y cuando no sea en modo arbitrario) si subsisten razones de interés general para la conservación en el ordenamiento jurídico, de institutos en este presentes, con independencia de los motivos que dieron sus orígenes. Este punto específico dio origen a una polémica entre Verzio Crisafulli y Carlo Esposito estribando en la cuestión de si es importante o no en sede de control constitucional, la sucesiva pérdida de la ratio legis de una ley. Cfr. Crisafulli, Osservazione, en Giur. Cost 1962, 43 ss. (favorable a una lectura de la ratio legis en el cuadro del ordenamiento objetivo y, por tanto, implícitamente favorable a la heterogénesis de los fines, Esposito, Gli art. 3, 41 e 43 della costituzione e le misure legislative e amministrative in materia económica, ivi, 48 ss. (defensor de la exigencia que la ley mantuviera una misma Ratio Legis siempre en línea con la constitución).

11 Traducción del latín. En italiano viene traducido como "Quante (sono) le teste, antrettanti (sono)i giudizi", en castellano vendría a ser "Mientras tantas sean las cabezas, tanto así serán los juicios de valor". (N. del T.)

12 MONETA, La cassazione civile e i suoi contrasti di giurisprudenza del 1990, en Contratto impr. 1992, 1245 ss.; Id, Mutamenti nella giurisprudenza della Cassazione Civile. Ottocentosessantasette casi di contrasto nel quinquennio 1988 - 1992, Padova 1993; Id.; Conflitti giurisprudenziali in Cassazione. I contrasti della Cassazione civile dal settembre 1993 al dicembre 1994, Padova 1995.

13 Limitándome al último caso, recuerdo que a través de una primera disposición, que ha recogido un reglamento contrario a una sentencia del tribunal de Boloña (Cass. 24 de Julio de 2001, n. 10086, 
Nos encontramos frente a un círculo vicioso: cuanto más aumentan los recursos, más aumentan los contrastes: Bien por la dificultad para los jueces llamados a conocer los precedentes más recientes, debido a la elefantiasis de la corte y de su desorden organizativo interno, o bien por las recientes señaladas intolerables divergencias sobre valores sometidos a la interpretación jurídica, que se verifican en la valoración de los diferentes colegas que rotan dentro de las "secciones"14. Pero cuanto más aumentan los contrastes, consintiendo a aquel que pierde en el "juicio de mérito" encontrar precedentes favorables, mientras más aumenten los recursos.

La garantía constitucional en el recurso de casación ha devenido en irracional porque se ha desintegrado la adecuación del instrumento respecto a su fin. Sería necesario abolirla, incluso porque esta se contrapone al principio del razonable tiempo del proceso frente a la Corte Suprema, a pesar de los ingentes recursos empleados, sobre todo para cuestiones orgánicas. Pero el tema es difícil, por razones que es inútil profundizar, aún más en un contexto de propósitos de reforma de nuestra Carta fundamental justamente en materia de justicia ${ }^{15}$. En relación a los intentos realizados por el legislador ordinario desde el 2006, destinados a deflacionar los recursos, desde el vínculo de las "secciones simples" a las precedentes "secciones unidas"16, a la duda de derecho y a la

en Corriere giur. 2001, 1435), sería adecuado dar una lectura sustancialmente abrogativa del número 19 del artículo 1469 bis c.c; la cláusula general que reserve la competencia al domicilio o a la sede del profesional no sería restrictiva ya que reproduce una disposición de ley, el artículo 20 c.p.c. cuando, como generalmente sucede, se verifiquen los presupuestos. Pero una sentencia inmediatamente sucesiva (Cass. 28 Agosto 2001, No 11282 en Corriere giur. 2002, 215, con comentarios de Conti, La cassazione ripensa al ruolo esclusivo del consumatore e abusività della deroga convenzionale alla competenzaper territorio: mai piu in giudizio lontano da casa) recibiendo una orientación emitido ya por la doctrina (cfr;; para todos, Dalmotto, Un nuovo foro esclusivo per il consumatore?, en giur it. 1997, IV, 161 ss., que pone oportunamente en consideración las aporías y círculos viciosos que dan lugar a las distintas interpretaciones) considera que, debiéndose evitar un resultado hermenéutico que transforme en inútil la disposición de la tutela del consumidor, incluso en interpretación conjunta con el artículo 1469 quater c.c., donde en caso de duda debe prevalecer la interpretación que le sea favorable, el n. 19 del artículo 1469 bis c.c. Se ha reconstruido como una disposición de carácter procesal que ha innovado la disciplina de la competencia introduciendo un nuevo foro exclusivo (pero derogable), que vuelve no aplicable el artículo 20 c.p.c. para las causas de los consumadores.

14 La organización en Secciones de la Corte, es similar a nuestra organización en Perú de la Corte en las Salas. Hay secciones de Civil, penal, etcétera y asimismo, las "secciones unidas" que serían las salas plenas. (N. del T.)

15 En el texto base sobre el sistema de garantías elaborado por la comisión bicameral para la reforma constitucional del 2002, se encuentra la propuesta de una norma sustitutiva del actual artículo 111 inciso 7, que admite el recurso en casación de sentencias únicamente en los casos previstos por la ley.

16 Es semejante a la Sala Plena. (N. del T.) 
sucesiva sustitución en el 2009 con un filtro de admisibilidad se está pronto para poder decir que hemos tenido éxito.

3. El principio de "justo proceso regulado por la ley": una clausula general que resume las garantias formales previstas en el articulo 111 del nuevo texto constitucional y al mismo tiempo "racionalmente" orientada a la justicia de la decisión.

Sucede de vez en cuando que la astucia del sistema va mucho más allá de las intenciones del legislador. En 1999, la ley de leyes ha sido modificada con una respuesta $a b$ irato del Parlamento a una singular sentencia del Tribunal Constitucional que, invocando el principio de no dispersión de la prueba, había declarado ilegítimo el artículo 513.2 del Código Procesal Penal en la parte en la cual sancionaba la inutilidad de declaraciones de personas imputadas con un "reato connesso"17 recogido en sede de indagaciones preliminares si a la disputa falta el acuerdo de todas las partes para su uso.

La ley constitucional, aprobada con amplia mayoría, tenía su punto de apoyo en una serie de normas sobre el procedimiento penal que, sin conformarse con enunciar el principio del contradictorio en la formación de la prueba -que habría sido susceptible de razonables excepciones por parte del legislador ordinario-, preveía analíticamente, con un incisivo proceder más de un código de ritualista que de carta fundamental, la imposibilidad de probar la culpabilidad del imputado sobre la base de las declaraciones de quien por libre elección ha renunciado al interrogatorio por parte del imputado o de su defensor, estableciendo también las relativas excepciones, taxativamente enunciadas.

Al mismo tiempo la ley ponía de manifiesto en su modificación del artículo 111 dos párrafos aplicables a todos los procesos. Se trata de un clásico ejemplo de dar un paliativo a un problema más complejo, con el evidente objetivo de insertar en un contexto más basto (y también más digno) la más específica revisión deseada por el Parlamento. El primero proclama que "la jurisdicción se aplica con el justo proceso regulado por la ley". El segundo que "cada proceso se desarrolla en el contradictorio entre las partes, en condiciones de igualdad, delante a un juez imparcial. La ley asegura el tiempo racionalmente debido.

17 La palabra "reato" no comprende solo el significado de delito, además comprende sanciones administrativas. Dicha palabra tampoco se limita no se reduce al ámbito administrativo, es decir, un reato no es sinónimo de falta. El "reato connesso" se asemeja al delito conexo. (N. del T.) 
Probablemente debido a la variación del preliminar que la intención del legislador debiera ser decisiva en el acto de reconstruir una nueva disciplina y porque persuadido de que la modificación del artículo 111 fuese un síntoma poco honorable del contraste que desde 1992 opone la política a la justicia en nuestro país, representando el epitafio simbólico a la situación conocida como "mani pulite", que había mostrado a la Fiscalía General de Milán procesar por corrupción y financiación ilícita a ciertas partes de sectores relevantes de la clase dirigente, había en un primer momento considerado que estas dos disposiciones tendrían el valor de las palabras llevadas al viento, al menos en lo referido al proceso civil ${ }^{18}$. Más precisamente estaba convencido que de la fundamental norma de comparación para las disciplinas procesales representadas por el artículo 24 de la Constitución y su conexión con el artículo 3 fueran recabables todas las garantías enunciadas por el artículo 111 inciso 2 según las cadencias más analíticas (incluso más allá, en cuanto enfáticas y por esta razón epicentro de inútiles complicaciones para el intérprete) ${ }^{19}$.

En suma, junto a otros escritore ${ }^{20}$, pensaba que no estuviesen en presencia de una refundación de los principios constitucionales del proceso y que por lo tanto no existieran normas en el proceso civil legítimas antes de la entrada en vigor de la ley constitucional $N^{\circ} 2$ del 23 de noviembre de 1999, e ilegítimas después. Llega a la misma conclusión poco después la Corte Constitucional ${ }^{21}$.

18 Cfr. Il nuovo artícolo 111 dellaCostituzione e il proceso civile, en Riv. Dir. Proc. 200, 1010 ss. ; Giusto processo e fallimento, en Riv. Trim. Dir. Proc. Civ. 2003, 453.

19 Es interesante evidenciar que, ocupándose del proceso penal Ferrua, Il processo penale dopo la riforma dell art. 111 della costituzione, en Quest. Giust. 2000, 30 admite de un lado, la necesidad de introducción de la garantía referida a la parte contraria en la formación de la prueba (que no se aplica al proceso civil) y de otro lado, la superfluidad de las otras reglas "confusamente acumuladas" en el artículo 111 Const. y destinadas a llamar la atención más que a resolver problemas.

20 DIDONE, Appunti sul giusto proceso di fallimento, en Il nuovo articolo 111 della Costituzione e il giusto proceso in materia civile, al cuidado de B. Capponi e V. Verde, Atti delconvegno di Campobasso (26 Febrero 2000) Napoles 2002, 105; Monteleone, Il processo civile alla luce dell'artícolo 111 Cost, en Giust. Civ. 2001, que considera que el nuevo artículo 111 de la Constitución tenga una eficacia declarativa y no constitutiva, estableciendo en modo explícito e incontrovertido aquello que ya constituía el presupuesto implícito de nuestro sistema judiciario; parcialmente en este sentido lo trata también Bove, Art.111 Cost e giusto proceso civile, en Riv dir, proc. 2002, 482, el cual afirma que "con la reforma constitucional a colación se han explicitado o aclarado mejor las garantías del proceso ya precedentemente recabables como implícito en el sistema constitucional"; y Cecchetti, Giusto proceso, en Enc. dir. aggiornamento, vol. V, Milán 2001, 618 quien sostiene que las únicas normas auténticamente nuevas introducidas en el artículo 111 son aquellas contenidas en los incisos $\mathrm{N}^{\circ} 4^{\circ}$ $\mathrm{y} 5^{\circ}$, relativas al proceso penal.

21 Corte cost. 28 Maggio 2001, n. 167 (ordenanza), en Giur. It 2001, 2233, con comentarios de Didone, Giusto processo, imparzialità del giudice e opposicione allo stato passivo: la Consulta non ci ripensa: Cote cost. 
Pero entonces, no había reflexionado suficientemente sobre el hecho que la inserción en el sistema provoca efectos que trascienden la intentio legis. Re melius perpensa, me he dado cuenta que un efecto de tal tipo se ha verificado en nuestro caso. He sentido así el deber de la autocrítica, justamente sobre la base de interrogantes basadas en la idea de racionalidad en profundizar el significado del justo proceso. Me he preguntado: ¿Es posible, que al introducir el nuevo principio la modificación de la Constitución continúe disciplinando un mecanismo para producir resultados, sin ocuparse de la bondad de estos últimos? Por ello que gracias al trabajo de una joven estudiosa ${ }^{22}$ he sentido el estímulo de ocuparme de las teorías anglosajonas sobre la justicia procesal con el objetivo de desarrollar las escasas intuiciones contenidas en la doctrina ${ }^{23}$ de sostener que el proceso es justo en la medida en que sea estructurado de modo que se oriente a producir resultados precisos, es decir, protocolos correctos desde el punto de vista de la solución -sea por una cuestión de hecho o bien de derecho- obviamente dentro de los limites consentidos en este mundo y en el respeto de las garantías. En el ámbito de una concepción cognitivista y no decisional del proceso jurisdiccional, donde la comprobación realística de los

31 maggio 2001, n. 176 (ordenanza) ivi.2001, 2014, con comentarios de Didone, La terziarietá del giudice nell'artícolo 146 l.f.

22 BERTOLINO, Giusto proceso civile e giusta decisione. Riflessioni sul concetto di giustizia procedurale in reazione al valore della accurateza delle decisioni giudiziare nel processo civile, tesis doctoral discutida en la universidad de Bolonia el 12 de Junio de 2007. Y v como Giusto processo civile e verità. Contributo allo studio della relazione tra garanzie processuali e accertamento dei fatti nel processo civile, Turín 2010.

23 Cfr. con paticular fuerza Taruffo, Poteri probatori delle parti e del giudice in Europa, en Riv. Trim. Dir. Proc. Civ 2006, 476 ss: "la idea según la cual el proceso debe tender a concluir con decisiones justas parece coherente con una interpretación no formal y no meramente repetitiva de la cláusula constitucional del justo proceso". Braccialini. Spunti tardivi sul giusto proceso, en Questione giustizia 2005, 1208: “¿cuando decimos proceso justo, nos referimos solo a las reglas procesales que garantizan la parte contraria, o bien tenemos en mente objetivos sustanciales del proceso y nos lleva a que eso sea un instrumento real de realización de derechos y no solo un instrumento sistemático para que sean ineficaces? ¿Y el juez es solo el árbitro de esta partida a armas normalmente desiguales, o no debería ser el garante de su justo resultado, es decir, la realización en concreto del derecho vulnerado? Yo creo que es ésta contribución conceptual el aspecto más significativo de todo el articulado, su estímulo más fecundo, ésta es la pregunta no evitable que todavía debería responder la doctrina procesal civil", Pivetti, Nardin. Un processo civile per il cittadino (Lineamenti di una proposta di reforma della procedura civile) en www.magistraturademocratica.it, en diciembre del 2005: "sucede también que el proceso se desarrolle en tal modo de tender hacia una decisión justa más allá de lo solicitado. "Justo proceso", efectivamente, no significa exclusivamente proceso de conformidad a las otras reglas específicas y a los otros principios expresamente consagrados por el nuevo artículo 111 o en otras normas constitucionales que implican al proceso". Es necesario revisar a Di Majo, La tutela civile dei diritti, Vol II, Milán 2001, 7: Carrotta, Prova e convincimento del giudice nel processo civile giusto e ragionevole, en Il nuovo art. 111 della costituzione e il giusto processo civile, cit 63. Remito a la conexión entre el Justo proceso y el deber de veracidad de las partes cfr. Comoglio, Etica e técnica del "giusto processo", Turín, 2004, 276. 
hechos constituya un ideal fundamental regulativo. Asimismo, las mismas garantías procesales mencionadas en el segundo párrafo del artículo 111 están estrechamente conectadas con la justicia de la decisión. Contradictorio e igualdad de las armas están pensadas también ${ }^{24}$ con el objetivo de crear, gracias a la dialéctica procesal, la solución justa de las cuestiones de hecho y de derecho deducidas a partir de la controversia 25 . Sobre la "terceridad" 26 y la imparcialidad como garantías, sobre todo, dirigidas a evitar decisiones desiguales, al respecto no es necesario recalcarlo en vano. No solo con el surgir de la injusticia que contamina la sentencia justa, siendo incluso una sentencia firme por decirlo de alguna forma fuera del tiempo máximo, quizás lustros después del episodio que ha dado origen a la controversia. Pero también porque, si pasa mucho tiempo entre la instrucción probatoria y la decisional, disminuyen las probabilidades de valoración correcta de la pruebas ${ }^{27}$.

Desde la interpretación ahora discutida se esgrime que el fin de justicia es el objetivo superior que la Constitución indica al enunciar que el proceso ha de ser justo en el primo párrafo del artículo 111 de la Constitución. La garantía de una tendencial decisión justa enerva un principio constitucional fundamental en materia de jurisdicción, junto a las garantías internas al proceso, contradictorio, igualdad de armas, la existencia de un tercero imparcial, el tiempo racionalmente debido del proceso contenidos en el segundo párrafo del artículo 111.

\section{El irrazonable ejercicio de "justo proceso" y la inexistencia de un deber de verdad de las partes, como también de una eficaz sanción po negación a obedecer a la orden de exhibición.}

El intérprete tiene entonces el deber de preguntarse si la disciplina positiva no pueda ser denostada por lagunas irracionales por la falta de instrumentos

24 Sin querer negar fundamento a la tesis de estos teóricos anglosajones de la justicia procesal que ponen un énfasis también sobre la valoración interna de las garantías procesales, sea desde el punto de vista de la satisfacción de los participantes por la corrección del tratamiento recibido. Para indicaciones bibliográficas cito cfr. Bertolino, Guisto processo civile e guista decisione, cit., 62 sgtes.

25 De fuerza epistémica del contradictorio trata Ferrua, Il guisto processo, $2^{a}$ ed.; Bolonia 2007, 91 sgtes.

26 Dicha palabra se refiere a la capacidad de ser tercero. (N. del T.)

27 Vale la pena recordar que Solum, Procedural Justice, en Southern California law rev, 2004, 78, 251 ss., Distinguiendo entre sistemic accuracy (la general corrección estática de los resultados de la actividad jurisdiccional) y case accuracy (la corrección de la solución del caso singular) hace un razonamiento análogo en relación a la disciplina de la prescripción, remarcando como la regla que obliga, con pena de extinción del derecho exaltado en juicio, a iniciar la controversia en un determinado tiempo es de gran ayuda para la primera, mientras la segunda viene salvaguardada por la oportuna difusión en el público de los contenidos de la subsiguiente disciplina. 
dirigidos a obtener una decisión justa. Naturalmente, es inútil proseguir, en un marco de respeto a las garantías internas del proceso.

La sentencia es justa cuando pasa la valoración de un criterio doble de verdad. Cuando esto es el fruto de una interpretación correcta de las normas y de una exacta reconstrucción de los hechos. Naturalmente, es el caso de remarcarlo si se quiere apartar la acusación de positivismo ingenuo, no se trata aquí de verdades absolutas, solo de un razonamiento matemático deductivo. Los criterios que entran en juego son criterios de aproximación por ambos sectores. Precisamente por esta razón la justicia procesal del proceso jurisdiccional es una justicia imperfecta, señalando al mismo tiempo la conexión con el perfeccionamiento del resultado y la imposibilidad de tener la absoluta certeza de alcanzarla ${ }^{28}$.

La certeza del racionamiento interpretativo depende de la bondad de la formación profesional asegurada a los jueces y de los controles en sede de impugnación, hasta la Corte de Casación, órgano de la nomofilaquia. Aquí no me parece que exista una relación que valga la pena que sea profundizada entre reglamentación del proceso y la certeza del decisum.

Las cosas cambian si miramos la disciplina del "juicio sobre el hecho". El justo proceso exige que la disciplina de las pruebas sea dirigida no tanto a asegurar la certeza de una exacta reconstrucción del hecho, cosa imposible; sino en cuanto a eliminar las fuentes de incertidumbre relativas a la reconstrucción, obviamente aquellas que son eliminables sin poner en riesgo las garantías constitucionales "internas": contradictorio, igualdad de las armas, imparcialidad del juez.

No corresponde a esta reconstrucción del concepto del justo proceso, ni la facultad consolidada de las partes de mentir tanto en sede de interrogatorio formal como en el interrogatorio libre, ni la disciplina de exhibición, que no prevé algún medio coercitivo para aquistar para el proceso los documentos en la disponibilidad de la parte que no pretende producirlos. A diferencia de cuanto sucede en los ordenamientos de common law, comenzando desde el norteamericano, a pesar de que está provisto de una constitución rígida que prevé las garantías obtenidas del principio del due process ${ }^{29}$. Ordenamientos

Cfr., Ferrua, Il giusto processo, cit, 67.

29 Pero también algunos ordenamientos del civil law se van orientando a esta dirección. Por ejemplo el code de procédure civile francés en el artículo 11 inciso $1^{\circ}$ dice que "Les parties sont tenues d'apporter leur concours aux mesures d'instruction sauf au juge à tirer tuoute consèquence dúne abstention ou d'un refus" y el inciso 2 dice "si une partie dètient un élément de preuve, le juge peur, à la requète de l'autre 
donde la parte puede ser llamada a testimoniar y la disciplina de la Discovery prevé duras sanciones, que llegan hasta la privación de libertad por contempt of court, en el caso que la parte no haga obtener al adversario toda la documentación relevante ${ }^{30}$.

$\mathrm{Al}$ respecto, la inexistencia de una obligación de la parte de decir la verdad ${ }^{31}$, bien en sede de alegación de los hechos, bien en sede instructiva es ya evidencia de la debilidad de la referencia a la onerosidad de la prueba, la inutilidad del principio nemo testis en causa propia históricamente condicionado a tiempos remotos y la inconsistencia del tradicional reclamo justificatorio al principio nemo tenetur edere contra se, cuya presentación va limitada al proceso penal ${ }^{32}$, como fundamento del privilege against self incrimination $^{33}$, sin necesidad de extenderla a los derechos de los privados, como señalan justamente los juristas anglosajones ${ }^{34}$. En relación a la ineficacia

partie, lui enjoindre de le produire, au besoin à peine d'astreinte. Il peut, à la rèquete d'une des parties, demander ou ordonner, au besoin sous la même peine, la production de tous documents dètenus par de tiers, s il n'existe pas d'empêchement legitime".

30 Para una reciente comparación entre ordenamiento italiano y el ordenamiento inglés cfr. Chiarloni, Riflessioni microcomparative su ideologie processuali e accertamento ella verità, in Riv.trim. dir.proc.civ. 2009, número especial Due iceberg a confronto: le derive di common law e civil law, 101 ss. Para un análisis de la actual disciplina de la discovery inglesa, donde son evidenciadas las características de la disclousure, con la atención dirigida a supuestos problemas de reconocimiento y ejecución que los relativos procedimientos podrían encontrar en los ordenamientos continentales, cfr. Zuffi, La disclosure inglese: aspetti comparatistici e trasnazionali, en Corriere giur. 2007, 35 sgtes.

31 En un ensayo de gran importancia, L'avoocato e la verità, actualmente en Il processo civile nello Stato democrático, Nápoles 2006, 131 ss.

32 Por un gran número de razones, examinadas atentamente por Bertolino, Giusto processo civile e giusta decisione, cit., 162 ss. Va olvidado que en la quinta enmienda la Constitución norteamericana limita al proceso penal el alcance del principio.

33 CAPPELletti, La testimonianza della parte nel sistema dell'oralità. Contributo alla teoria della utilizzazione probatoria del sapere delle parti nel processo civile, Vol. II, Milán 1969, 236 e 380.

34 Cfr., por ejemplo, Langbein, The Historical Origins of the Privilege Against Self Incrimination at Common Law, en Mich. Law rev. 1994, 1047 ss., citado por Bertolino. Op. ult. Cit., 166, nota 87. Para no correr el riesgo de caer en la falacia naturalística, no es necesario ser contrario a que no habría sentido en hablar de una "peculiaridad penalística" del principio nemo tenetur, en cuanto constituiría "solo una faceta de una más que general garantía de la parte de cada fenómeno procesal. De esta forma Consolo, en Postilla...sed (e quando) magis amica veritas?, en Corriere giur. 2007, 45. Va recordado que también según Consolo, esta "garantía" es insistente, aunque con prudencia, por ejemplo introduciendo el deber de la verdad a cargo de determinadas partes: "sociedad que atrae el mercado de capitales y orientada hacia la transparencia informativa, ente público sujeto al acceso; productor de bienes de largo consumo; asociaciones pro bono actoras en procesos de relevancia colectiva, protección concursal". Una discreta tipología, no hay lugar a dudas. Faltan sin embargo indicaciones sobre las sanciones adecuadas por violación de la obligación. No creo que la responsabilidad agravada sobre la que se basa sea suficiente. Vista la recurrente aceptación de su aplicación para los casos donde está actualmente prevista. 
del orden de exhibición, no ejecutable forzadamente y sin previsión de las medidas coercitivas debido a la falta de ejecución espontánea, parece notorio el contraste con el derecho de defenderse probando, al menos todas las veces que la parte interesada no disponga de otros medios de prueba. Aquí deviene difícil imaginar que cualquier garantía interna al proceso se interponga a una disciplina que asegure con sanciones adecuadas el cumplimiento del relativo procedimiento del juez. Sin contar la gran importancia -y diría urgencia de introducir la coercibilidad del orden de exhibición- en relación a la reciente introducción de la denominada "acción de clase" donde muy frecuente son los citados en el juicio, demandados (si piensas en los bancos y a los seguros) quienes tienen la disponibilidad de gran parte de la documentación relevante.

Para concluir, sobre todo respecto al tema de exhibición, pero quizás también por las obligaciones de las partes, la irracional tendencia a la existencia de lagunas de la disciplina positiva debería llevar a una intervención del Corte Constitucional, con un procedimiento de acogimiento conocido como manipulativo, que declare aquella disciplina considera ilegítimo, en cuanto no dispone la coercibilidad del orden de exhibición y no dispone del testimonio de las partes, además de una obligación de verdad en las alegaciones y en las declaraciones hechas en sede de interrogatorio.

\section{Equilibrio entre derecho de acción y derecho de defensa en la disciplina de las notificaciones.}

La racionalidad constitucional impone que las garantías procesales tengan en consideración de forma equilibrada los intereses de ambas partes que se ven contrapuestas en una controversia. Bajo este perfil es fundamental que los actos dirigidos a ponerlos en contacto sean regulados para asegurar en los límites de lo posible el conocimiento del acto introductorio del proceso por parte del demandado. Con este objetivo actúan las disposiciones del código de rito que disciplinan los requisitos de las notificaciones y los vicios relevantes por su ausencia. Naturalmente, también en presencia de estos vicios, la racionalidad quiere que estos devengan irrelevantes si el demandado se constituye así, reequilibrando las recíprocas posiciones. Esta, la ratio de la norma en materia de saneamiento ${ }^{35}$ de las nulidades por obtención del objetivo. Probablemente por una influencia del clima autoritario en el cual la disposición fue emanada, el artículo 11 párrafo $1^{\circ}$ del R.D. 30 octubre de 1933, n. 1611, según la consolidada interpretación de la Casación, excluía la del saneamiento por

35 Institución jurídica italiana que se encarga de sanar un acto administrativo ilegitimo porque está privado de requisitos esenciales previsto por el ordenamiento. (N. del T.) 
haber conseguido el objetivo las nulidades de las notificaciones a la administración pública. El desequilibrio que de esta forma se determinaba ha sido cancelado por la Corte Constitucional con la sentencia n. 97 de 1967, que con el conquistado clima democrático no podía considerar razonable el trato desigual en este sector entre administración pública y común ciudadano.

Siempre respecto al tema de las notificaciones, el "óptimo equilibrio" de los contrapuestos intereses de notificante y notificado, esta vez sobre la base de un análisis de las consecuencias en el caso concreto, ha sido recientemente realizado por la Corte Constitucional con la sentencia del 26 de enero de 2010, n. 3. La declaración de ilegitimidad constitucional del artículo 140 c.p.c, por violación del artículo 3 Const., inc. $1^{\circ}$, y del artículo 24 Const., inc. $2^{\circ}$, en la parte en la cual se prevea que la notificación se perfecciona, para el destinatario, con la expedición del correo certificado informativo, en vez que con su recepción, o de todas formas, transcurridos diez días de la relativa expedición, viene motivada remarcando que la disposición, haciendo discurrir para el destinatario del acto notificado los términos para actuar a su defensa desde un momento anterior al concreto conocimiento del acto, daba lugar a un "irracional equilibrio entre los intereses del notificante (...) y aquellos del destinatario, en una materia donde las garantías de defensa y de tutela de la contraparte deben ser impresos con cánones de efectividad e igualdad".

\section{El formalismo de las garantías.}

Desde hace mucho tiempo escribo sobre "formalismo de las garantías". Con esta fórmula pretendo connotar que los casos donde el formalismo procesal, un mal que puede convertirse en instrumento del daño causado según las palabras de Hegel $^{36}$, se camufla detrás de la santidad de los principios sancionados por la Constitución desde el 1948 en el artículo 24 y recientemente más analíticamente articulados por el nuevo texto del artículo 111 bajo la noción del justo proceso. Con la consecuencia de arruinar las garantías, de sede de justicia por causa de injusticia o de injusta dilación en la decisión. Entre los casos tratados en el pasado ${ }^{37}$ cito dos, que considero de gran interés.

7. Una reconstrucción irrazonablemente desequilibrada en las relaciones entre principio de razonabilidad duradera del proceso y derecho de acción.

\footnotetext{
${ }^{36}$ ‘Cfr. Lineamenti di filosofia del diritto, trad. it. $4^{\text {a }}$ ed. Bari 1971,193.

${ }_{37}$ ‘Cfr. Formalismi e garanzie. Studi sul processo civile, Turín.
} 
Como el segundo inciso del artículo 111 Constitución Proclama que "la ley asegura la racional duración del proceso" tendremos que esperar una disciplina gracias a la cual: si un ordenamiento procesal pone a disposición más medios para obtener el mismo resultado útil, entonces, se debe recurrir al medio más simple, es decir aquello que comporta un menor empleo de tiempo, además de un menor uso de recursos.

Por ejemplo, podemos imaginar que se tenga que usar el procedimiento por "decreto ingiuntivo" 38 en vez que el procedimiento ordinario si existen los relativos presupuestos; y que se tenga que iniciar directamente el procedimiento de ejecución forzada, en lugar de recurrir al "decreto ingiuntivo" o iniciar un proceso ordinario si el acreedor posee un título ejecutivo.

Obviamente, no sería oportuno impedir directamente a la parte el uso del medio más costoso en término de tiempo y de uso de los recursos a través de alguna sanción como la no procesalidad. Se verificaría un conjunto de complicaciones superiores de aquellas que se desean evitar.

Bastaría introducir medios indirectos de persuasión: determinar que, si la parte quiere usar un medio, que ocasiona un mayor dispendio de los recursos jurisdiccionales respecto a aquellos menos dispendiosos a su disposición, lo hará a expensa propia.

El legislador había ya intentado algo similar con la ley del 10 de mayo de 1976, n. 180, que, modificando el artículo 641 en el último párrafo del c.p.c. había determinado que en el "decreto ingiuntivo" emanado sobre la base de los títulos ya cargados de eficacia ejecutiva no vengan liquidados los gastos y los honorarios, solo liquidable en el caso del rechazo de la sucesiva eventual oposición.

Pero el problema es que, con la sentencia n. 303 del 1986 de la Corte Constitucional ha declarado inconstitucional la norma sobre la base de una motivación en pocas líneas, donde encontramos escrito que la ilegitimidad por violación de los artículos 3 y 24 de la Const. "deriva de aquello que la ejecutoriedad provisoria del decreto justificada por ser el acreedor munido de título ejecutorio no deja de ser legitimada por el acogimiento de la demanda, de la cual es normal complemento la liquidación de los gastos y de las competencias en defecto de la cual el derecho de actuar en juicio, por una vieja

38 Se trata de una orden dada por el juez con la finalidad de constreñir a un sujeto de cumplir su obligación inmediatamente. (N. del T.) 
enseñanza sería en un modo incompleto garantizado (aquí me parece evidente la referencia al viejo, pero no así vetusto discurso de Chiovenda, donde el demandante que tiene razón debería hacer valer su derecho en el juicio "este, propio este y por completo" que habría obtenido gracias al cumplimiento espontáneo del deudor).

Estas pocas pero autorizadas palabras no han provocado la reacción que se esperaba.

Pero si reflexionamos un poco sobre lo citado, deberíamos ser capaces de darnos cuenta de que estamos en presencia de un eminente caso de formalismo de las garantías.

Dejo en relieve que en este modo se propone una interpretación del derecho de acción tal de encerrar en sí mismo el "principio de soccombenza"39 , cuestión ya per sé discutible, visto que existen ordenamientos con constituciones rígidas atentas a las garantías procesales como el caso norteamericano que no dispone la condena a los gastos a favor de la parte vencedora ${ }^{40}$.

Me limito a observar que el derecho de acción en sede de cognición no merece protección constitucional cuando ya se es ya titular del derecho a actuar para la ejecución forzada. Esto por obvia instrumentalidad del primero al segundo derecho, desde la visión de la utilidad que afectar al acreedor. Y no serviría objetar que con la acción de cognición, se obtendría resultados como la "definibilidad" del control que deriva de lo enjuiciado o la verificación de la hipoteca judicial, que no se obtiene actuando in executivis.

Se trataría de objeciones que denuncian la mentalidad abstracta que a veces aflige a nuestra doctrina.

De lo enjuiciado al acreedor no se ve aventajado si obtiene el bien de la vida perseguido con ejecución forzosa. En caso contrario podrá perseguirlo frente a cualquier sucesiva reacción procesal del deudor, por ejemplo si fuese propuesta la oposición a la ejecución.

En referencia a la hipoteca judicial, me parece justo que el acreedor, que puede proceder al embargo inmobiliario con su título, pague los gastos por el plus de

39 Es el principio según el cual corresponde a la parte que pierde en el juicio ("soccombente") y a favor de la parte que ha vencido la responsabilidad por los costos y costas del proceso. (N. del T.)

40 También en los Estados Unidos se discute sobre la oportunidad de introducir el principio de sucumbir, operativo en Tejas en materia de responsabilidad civil, en vista al objetivo de la deflación de los casos de medical malpractice. Cfr. Tort reform, en The economist 10 - 16 de Diciembre de 2011, 43. 
ventaja que puede resarcirse de la hipoteca, que no representa seguramente un derecho de acción, sino de un efecto secundario.

\section{La sanción de nulidad irrazonablemente aplicada a las sentencias de la tercera vía a causa de una errónea aplicación del principio del contradictorio}

En las elaboraciones frecuentes de la doctrina, hechas recientemente como propias por el legislador procesal, encontramos un segundo caso de formalismo de las garantías y por tanto de irracionalidad que ha suscitado la disciplina. Aludo al segundo inciso del artículo 101 c.p.c. introducido por la ley 69/2009, que fulmina con la conminación de la nulidad las sentencias de la tercera vía. La nueva norma dice que "se considera que pone como fundamento a las decisiones una cuestión considerada de oficio, el juez se reserva la decisión, asignando a las partes, bajo pena de nulidad, un plazo, no inferior a 20 y no superior a 40 días, para el depósito en la secretaria judicial de memorias que contengan observaciones sobre la misma cuestión".

La norma ahora introducida tiene detrás de sí una larga historia, que haría exclamar con satisfacción a Rodolfo Sacco que aquí nos encontramos frente a un ejemplo eminente de una doctrina que se transforma en "fuente de derecho" ${ }^{\prime 4}$.

Desde 1968 un autorizado escritor, Vittorio Denti42, acompañado en los años sucesivos por un equipo bastante sólido (entre otros Ferri, que al problema ha dedicado una entera monografía, Tarzia, Comoglio, Lanfranchi, Cavallini, Luiso, Civitini, Fabiai, Proto Pisani, e Consolo) sostenía la tesis de la nulidad de la sentencia emanada por el juez sobre cuestiones anteriores al juicio relacionadas al proceso o cuestiones preliminares de mérito de oficio susceptible de ser relevante, no susceptibles a la discusión de las partes. La nulidad puede darse en cualquiera en modo intuitivo, por violación de la parte contraria, garantía constitucional fundamental en el proceso, aunque en aquellos tiempos no codificada de forma expresa, como había sucedido en el 1999 con la reforma del proceso justo, pero afirmada de manera consolidada en la jurisprudencia del Corte Constitucional en sede de interpretación del artículo 24.

41 Cfr. La dottrina fonte del diritto, en Studi in memoria di Tarello, II, Milán 1990, 449 ss. I principi generali nei sistemi giuridici europei, en Atti del convegno sui principi generali del diritto organizzato dall' Accademia nazionale del Lincei, Roma 1992, 170. Algunas antocaciones críticas mías en La doctrina fonte del Diritto? En Riv, trim, dir, proc, civ 1993, 439 sgtes.

42 En Questioni rilevabili d' ufficio, diritto di difesa e "formalismo delle garanzie" en Riv. Trimestrale Diritto processuale civile 1987. 
Con algún retraso, creo que desde el 2001, la jurisprudencia de la Casación lo ratifica, con alguna modesta oscilación.

Por más de veinte años hube de ocuparme de esta tesis porque me parecía que a causa de su carácter absoluto con que venía entonces enunciada era un caso típico de formalismo de las garantías. Cierto, es innegable la existencia de un deber preciso del juez de someter a la discusión entre las partes las cuestiones que entendiera considerar de oficio. Sancionable en vía disciplinar, según las indicaciones que nos vienen del artículo 124 c.p.c., segura expresión de un principio general del universo procesal, donde dice que "los magistrados están obligados a observar las normas de este código como también la no observancia no conlleva nulidad u otra sanción procesal" y "los dirigentes de las oficinas vigilan sobre la observancia de las normas también por responsabilidad disciplinar".

Pero no llegaba a ser capaz de ver una violación del principio del contradictorio en la emanación de una sentencia de la tercera vía, considerada en sí y para sí. La cuestión relevada de oficio, decía entonces, no es cuestión de oficio, perteneciente a un misterioso patrimonio de sus conocimientos esotéricos. Es una cuestión siempre resolvible en base a nociones, jurídicas o de hecho, que pertenecen a un patrimonio de conocimientos comunes al juez y a las partes, mejor dicho a sus abogados. Deriva de esto que, por no tener el juez indicado la cuestión no constituye la causa de la ausencia de contradictorio sobre ésta, de revisar más que considerar una insuficiente atención de los defensores, y en particular modo del defensor de la parte contraria respecto a las consecuencias de su importancia. Por esta razón, cuando los defensores saben hacer bien su trabajo, las cuestiones relevadas de oficio, antes de que el oficio las reconozca, son dejadas al margen de las partes, tanto que la doctrina ha sentido la necesidad de diseñar una categoría conceptual para esta actividad, instituyendo la species de las excepciones en sentido impropio o exceptiones facti.

De manera contraria respecto de aquello que podría parecer, la no observancia del deber del juez de estimular la parte contraria sobre cuestiones relevadas de oficio no pone en juego, por sí mismo, (es decir excepto los casos, raros, estoy convencido, donde el reconocimiento oficioso ha impedido la posibilidad de concretos y ulteriores desarrollos de las alegaciones de las partes) el principio del contradictorio y la correlativa nulidad que sanciona su falta de respeto. Tratándose del deber de solicitar la previa discusión sobre cuestiones que pertenecen al patrimonio del común conocimiento de todos los sujetos del proceso, el principio que viene en consideración es otro, cuya transgresión no 
comporta (y sería irrazonable que comportase) la nulidad de la sentencia. Se trata del principio de recíproca colaboración del juez con las partes con el fin de garantizar la leal conducción del proceso y la justicia del procedimiento, un principio que la doctrina desde hace tiempo ha individualizado como un componente inspirador importante de las modernas disciplinas procesales.

La precisión de esta conclusión se ve mejor si tomamos en consideración cuál fuese el real significado de las tesis favorables en absoluto a la nulidad en el ámbito de los juicios de impugnación.

Suponemos que la sentencia sea de lejos injusta porque el juez ha errado en resolver la cuestión relevada de oficio; en tales casos es posible, y quizás probable, que el no haber abierto el espacio al ejercicio del derecho de defensa de las partes; por consiguiente, haya contribuido en modo determinante a la comisión del error. Pero, evidentemente, aquello que en primer lugar se ha de considerar es solo este error, que se intentará subsanar en el sucesivo grado de impugnación. También desde el punto de vista el interés de las partes, la pretendida violación del contradictorio queda como cuestión de fondo, pierde absolutamente relevancia. La parte no pensará ni tan siquiera objetarla por motivos de gravamen, porque el orden lógico de las cuestiones impondría antes de relevarla, quizás con alguna consecuencia desagradable de frente a la Casación.

La verdad es que el problema de una autónoma valoración del vicio que estoy analizando es susceptible de ser puesto en el caso en el cual el juez no ha presentado a previa discusión de las partes la cuestión elevada de oficio, y sin embargo, al mismo tiempo, la ha resuelto correctamente.

Sobre el plano de la apelación, se releva que la censura relativa a la falta de activación del contradictorio no puede ser de ninguna utilidad para la parte sucumbiente, siempre y cuando no tenga motivos para lamentar la sustancial injusticia de la sentencia impugnada. El apelante no podrá obtener entonces, en tal caso ni la remisión en primer grado, indicada la taxatividad de las hipótesis previstas por los artículos 353 y 354 c.p.c, ni la renovación de actos sobre la base de lo dispuesto tanto en los artículos 354 inciso 4, como en concordancia con el 356.

Obtendrá esta renovación, particularmente importante por lo que refiere a la remisión en términos por las instancias instructoras, si y solamente podrá lamentar que el acto de elevación oficio sin una previa estimulación del contradictorio ha impedido ulteriores alegaciones necesitadas de prueba que habrían sido capaces de orientar la sentencia de primer grado hacia un 
resultado para él favorable, a pesar de la corrección de la solución de oficio (he reivindicado la propiedad sobre la base de un contrato que es nulo y entonces hago valer la usucapión). Sobre el plano de la Casación las cosas deberían ser de forma distinta, debido a que es una paradoja de la actual disciplina de nuestro juicio de legitimidad con escisión orgánica entre la fase rescindente y la fase rescisoria la necesidad de acoger la impugnación en toda una serie de casos (cuando no sea posible la decisión sobre la base del anterior Art. 284, párrafo $2^{\circ}$ c.p.c.) donde los mismos motivos puesto como base de esta, no obtendrán ningún resultado útil si son propuestos delante de un juez de un gravamen sustitutivo como la apelación.

Sin embargo, incluso con referencia a la Casación es posible ver algún argumento para contestar una reconstrucción de la disciplina por la cual la falta del contradictorio preventivo sobre las cuestiones relevadas de oficio vicia, sin necesidad de otra consideración, el proceso y la sentencia.

Es necesario ejercitar el ars distinguendi. De esta forma nos encontraremos frente a cuatro alternativas:

a) La sentencia impugnada en Casación es justa bajo cualquier imaginable perfil, y entonces predicar de esta la nulidad con necesario consideración con reenvío del recurso del sucumbiente. Que la llegue hacer valer parece como fruto de un comportamiento formal que acaba, como dice Hegel, convertido en el instrumento de injusticia, porque serían premiados los intentos dilatorios de la parte que ha estado en error. A este propósito basta pensar en el caso donde el juez que revisa la apelación declara correctamente de oficio, pero sin el contradictorio, el defecto de jurisdicción (me parece, como a muchos, errada la reciente jurisprudencia que ha realizado una interpretación abrogativa del artículo 37 c.p.c.). Tendremos la paradoja de una Corte de Casación, órgano superior regulatorio de la jurisdicción, investida por la nulidad en el sentido del artículo 101 párrafo 2 y por consiguiente, obligada en acoger mediante el reenvío el recurso, no teniendo la Corte ningún poder de sustitución de las sentencias inválidas.

b) La sentencia impugnada delante del Supremo es injusta por haber resuelto el juez de mérito erróneamente la cuestión realizada de oficio, y entonces existirá de todas formas el espacio para obtener la anulación abstrayendo de la pretendida violación del contradictorio, convertida irrelevante y proponiendo el medio de recurso orientado a denunciar el vicio existente. 
c) La sentencia impugnada en Casación es injusta per errada resolución de la cuestión relevada de oficio, pero la injusticia puede avenir solamente después de nuevas alegaciones de parte, impedidas por la faltante previa de estimulación del contradictorio. Caso típico, recodado por Francesco Luiso, aquel de la elevación de oficio de nulidad de una cláusula abusiva, que podría haber sido superada demostrando la advenida tratativa individual especificada por el artículo 34 inciso $4^{\mathrm{a}}$ del Código del Consumo. Aquí las consecuencias serán análogas a aquellas indicadas aquí abajo.

d) La sentencia impugnada en casación es injusta, a pesar que la cuestión alzada de oficio sea resuelta correctamente sobre la frecuencia estadística de un caso de esta naturaleza que debiera tratarse de casos de extrema rareza. Consideramos que, como en el caso anterior, puede solamente referir la solución exacta de una cuestión preliminar de mérito, pero jamás la exacta solución de una cuestión preliminar respecto del proceso. Se trata de los casos donde la cuestión realizada de oficio ha sido correctamente resuelta, pero la sentencia es igualmente injusta, porque, no habiendo el juez estimulado al contradictorio sobre la sentencia, ha impedido a la parte la modificación de la demanda consentida que habría obtenido de todas formas con un resultado favorable. Junto a aquel precedente, este será el segundo caso donde se tendrá una valoración autónoma por la falta de estimulación del contradictorio sobre la cuestión realizada de oficio, en este caso resuelta correctamente: y también aquí se ha de concluir para acoger el recurso dirigido a la anulación de la sentencia impugnada, a condición de que articule con precisión la amputación de la historia procesual causada por la valoración solitaria de la cuestión. $\mathrm{Y}$ en esta dirección restrictiva se ha orientado de manera oportuna el "juez de legitimidad" en sus más recientes pronunciamientos.

Podemos pues sintetizar el argumento de esta manera: la previsión de nulidad de la citada sentencia de la tercera vía necesita una interpretación correctiva que sigue las líneas de interpretación de las más recientes sentencias de la Corte de Casación antes de esta intervención del legislador que, en el querer codificar una dirección jurisprudencial, lo ha hecho más rígido, sin hacer ninguna mención de las citaciones apenas recordadas. Hasta que el vicio sea declarable en sede de gravamen, no basta la solución solitaria de una cuestión obrada por el juez. Es necesario, como siempre, el intereses a impugnar. Que en nuestro caso asume una connotación particular cuando en juez haya resuelto 
correctamente la cuestión (o bien, si ha errado, cuando la injusticia pueda surgir a raíz de ulteriores alegaciones de parte, impedidas por el "relievo oficioso"43 ex abrupto). La violación del contradictorio debe ser tal de haber impedido a la parte de recurrir a la controversia, con sucesivas alegaciones, un camino alternativo que consiente de alcanzar la deseada victoria. El nuevo texto del artículo 360 bis número 2 del Código Procesal Penal puede contribuir quizás a esta solución, en la medida en la que exige que el vicio de la sentencia impugnada por razones procesales determine una violación de los principios reguladores del proceso justo.

Sin embargo, no estoy seguro que esta interpretación correctiva u otra, aún más ingeniosa, recientemente esgrimida por Claudio Consolo que individua una curiosa forma de saneamiento (procedimiento donde el juez o jueces renuncia o renuncian a actuar legalmente en contra de los responsables de acciones ilegales o normalicen situaciones precarias o irregulares) ex post de la nulidad, serán unánimemente compartidas. Se podrá siempre encontrar algún intérprete o juez capaz de objetar, con base en la colocación sistemática del artículo 101 inciso 2, que la violación del principio del contradictorio, por haber el juez de segundo grado decidido en cuestiones de oficio sin ponerlo de manifiesto a discusión de las partes, debe ser siempre sancionada por el juez de legitimidad, con absoluta indiferencia al hecho de que la violación haya o no influido sobre la justicia de la sentencia. Más allá de la sentencia de tercera vía, no solo en campo penal, donde son legiones, sino también en campo civil la fantástica casuística de los recurrentes que han encontrado audiencia de la Corte Suprema nos muestra ejemplos.

43 Che cosa significa "Rilievo d'ufficio"? ¿Qué cosa es el "relievo de oficio"? Se trata de una capacidad que corresponde al juez que tiene a cargo la causa que consiste en el poder de efectuar las elecciones necesarias sea en el plano procesal como en el plano sustancial (por ejemplo respecto al defecto de jurisdicción y la nulidad del contrato) incluso sin que haya sido evidenciada alguna excepción, corresponde al art. 1297 del C.C. italiano. http:/ / www.brocardi.it/dizionario/3446.html. En el texto es también traducido como valoración [del juez]. (N. del T.). 